\title{
DERLEME
}

\section{Pediatri Yoğun Bakımlarda Deliryum Yönetiminde Hemşirenin Sorumlulukları ve Rolleri}

$$
\text { Illçim ERCAN }{ }^{1} \text {, Evrim KIZILER }{ }^{2}
$$

\section{$\ddot{O Z Z}$}

Deliryum, bilinç durumunda dalgalanmaya neden olan akut başlangıçlı mental bir durumdur. Yoğun bakım ünitelerinde tedavi gören çocuk hastalarda, ortamın gürültülü ve sürekli aydınlık olması, tıbbi cihazların varlığı, sağlık ekibinin tekrarlayan müdahaleleri ve mekanik ventilasyon ihtiyacı gibi nedenlerle görülme sıklığı \%80'e kadar çıkmaktadır. Çocuk hastalarda deliryum yüksek mortalite oranlarıyla ilişkili, sık görülen bir sağlık sorunu olmasına rağmen çocuk gelişim düzeylerindeki farklılıklar, bilgi eksik liği, yapılan çalışmaların azlığı ve rutin değerlendirmede aksamalar nedeniyle pediatrik deliryum vakaları sağlık ekibi üyeleri tarafından ya erken dönemde fark edilememekte ya da depresyon gibi farklı bir tanı ile karıştırılabilmektedir. Bu durumda tablo daha da ilerlemekte, çocukların oryantasyonu, düşünce süreçleri, uyku düzenleri bozulmakta, hastanede kalış süresi uzamakta ve hatta hasta kaybedilebilmektedir. Yoğun bakımda tedavi gören çocuk hastalarla tedavi ve bakım gereği sürekli temas ve iletişim halinde olan hemşireler, hastada oluşabilecek ufak bir değişikliğin bile fark edilmesi, pediatrik deliryumun erken dönemde tanılanması ve tedavisinin sağlanmasında kritik rol oynamaktadır. Bu derlemede hemşirelerin pediatri yoğun bakımlarda deliryum yönetimindeki sorumluluk ve rollerinin vurgulanması amaçlanmıştır.

Anahtar Kelimeler: Deliryum; Hemşirelik; Pediatrik Yoğun Bakım Ünitesi

\section{Nursing Responsibilities and Roles in Delirium Management in Pediatric Intensive Care Unit İlçim ERCAN ${ }^{1}$, Evrim KIZILER ${ }^{2}$}

\begin{abstract}
Delirium which causes fluctations in consciousness is an acute mental state. Pediatric patients who treated in intensive care units, the incidence increases up to \%80 because of noisy environment, permanent bright environment, presence of medical devices, repetitive intervetions of healthcare team and need for mechanical ventilation. Although delirium is a common health problem associated with high mortality rates in pediatric patients, not be noticed by healthcare team in early period or is mixed up with a different diagnosis such as deppresion due to differences in developmental levels, lack of information, minority of studies and hitch of routine evaluation. In this case, the status progresses further, orientation, thouht processes and sleep cycle decay, the duration of hospital stay is prolonged and even the patient may be died. Nurses, who are in constant contact and communication with pediatric patients who are treated in intensive care accordingly treatment and care, play a critical role in recognizing even a small alteration that occur in patient, early diagnosis of pediatric delirium and providing treatment. In this review, it is aimed to emphasize the responsibilities and roles of nurses in delirium management in pediatric intensive care units.
\end{abstract}

Keywords: Delirium; Nursing; Pediatric Intensive Care Unit

'Acıbadem Üniversitesi, Sağlık Bilimleri Fakültesi, Hemşirelik Bölümü, İstanbul, Türkiye.

${ }^{2}$ Ankara Yıldııım Beyazıt Üniversitesi, Sağlık Bilimleri Fakültesi, Çocuk Sağlığı ve Hastalıkları Anabilim Dalı, Ankara, Türkiye. Sorumlu Yazar: İlçim ERCAN

E-posta adresi: ilcimercan@hotmail.com ORCID No: 0000-0001-7604-8447

Gönderi Tarihi: 28.11.2020 Kabul Tarihi: 02.12.202 


\section{GİRiş}

Deliryum, akut başlangıçlı, bilinç, dikkat ve farkındalıkta bozulma ile karakterize, tıbbi bir durumun ya da tedavinin sonucunda meydana gelen ve gün içinde belirtilerinde dalgalanma görülen organik ve mental bir sendromdur $(1,2)$. Ciddi beyin fonksiyon bozukluğu ile karakterize olan deliryum sıklıkla yoğun bakım ünitelerinde görüldüğü için "yoğun bakım psikozu" ya da "yoğun bakım sendromu" olarak da adlandırılmaktadır $(3,4)$. Ruhsal Bozuklukların Tanısal ve İstatistiksel El Kitabı (DSM-5) ve Uluslararası Hastalık Sinıflamasına (ICD-10) göre deliryum tanısı için (a) akut gelişmesi, (b) dikkatte, bilişte ve farkındalıkta bozulma olması, (c) altta yatan başka bir tıbbi durumun sonucu olarak görülmesi, (d) belirtilerin gün içerisinde dalgalanma göstermesi ve (e) farklı nörokognitif bir durumla açıklanamaması gerekmektedir $(5,6)$. Bilişsel gerilemeye, kendi kendine ekstübasyona, hastanın hospitalizasyon ve mekanik ventilasyon desteği süresinin uzamasına, mortalite ve morbidite oranlarının artmasına neden olan deliryumun pediatrik popülasyonda görülme sıklığı \%10-60 arasında değişmekte; özellikle entübe olan ve cerrahi operasyon geçirmiş çocuklarda \%80’e kadar çıkabilmektedir (3-5). Pediatrik deliryum öncelik sırasına göre zaman, mekân ve kişi oryantasyonunun bozulmasına yol açmakla birlikte belirti ve bulgular deliryumun tipine göre de farklılık göstermektedir $(7,8)$. Çocuklarda en sık görülen hipoaktif deliryumda tüm psikomotor faaliyetlerde ve uyanıklıkta azalma görülür (7). Çevreye karşı ilgisizdir, az konuşur, sık sık uyuklar, göz teması kurmazlar (4,6,7). Hiperaktif deliryumda; artmış otonomik ve sempatik sinir sistem aktiviteleri göze çarpar. Ajitasyon, sinirlilik, heyecanlılık, saldırganlık davranışlarına yansımıştır. Yatakta kalmak istemez, bağırır, kendisine ve çevresine zarar verecek davranışlarda bulunur. Çok belirgin illüzyonları, halusinasyonları, hezeyanları vardır. Kooperasyon kurmak güçtür $(4,6,9)$. Her iki tip deliryumun yaşandığı karma tipte ise gündüz hipoaktif, gece hiperaktif deliryum belirtileri arasında dalgalanma gösterirler $(4,6,7,9)$.

Deliryumun patofizyolojisi henüz tam olarak bilinmemesine rağmen; ortaya çıkan nörokognitif bozuklukları açıklamak için çeşitli teoriler vardır (7). $\mathrm{Bu}$ teorilerden birincisi geriye dönebilir 
serebral oksidatif metabolizma bozukluğudur

$(10,11)$. Hipoksi, nörotransmitterlerde dengesizlik, inflamasyon, stres tepkisi, toksik ve metabolik nedenlerle serebral oksidatif metabolizma bozularak beyin fonksiyon bozukluğu belirtilerine yol açmaktadır $(3,4,12)$. Başka bir hipoteze göre ise; başta asetilkolin, dopamin ve Gammaaminobutirik asit ( GABA ) olmak üzere çoklu nörotransmitterlerin anormallikleri deliryuma neden olmaktadır $(10,11)$. Dopamin nöronların uyarılabilirliğini artırırken, GABA ve asetilkolin azaltmaktadır. $\mathrm{Bu}$ dengede bozukluk olduğunda nöronal stabilite bozulmaktadır $(4,9)$.

Pediatrik deliryumun gelişiminde hastayı savunmasız hale getiren predispozan (yatkınlaştıran) faktörler ile deliryum gelişimine akut olarak zemin hazırlayan presipitan (tetikleyen) faktörler birlikte rol oynamaktadır (Tablo 1) (13$15)$.

Predispozan faktörler arasında özellikle erken yaşta olma deliryum açısından önemli bir yere sahiptir (2). İki yaş altında kritik hastalığı olan çocuklarda deliryum görülme sıklığı \%56'ya kadar çıkmaktadır (9). Enfeksiyonlar, ağrı, sepsis, metabolik bozukluklar, otoimmün hastalıklar, sıvı elektrolit bozuklukları, yanık, malnutrisyon, hipoperfüzyon, hipoksi/anoksi ve hemodinamik dengesizlikler (hipotansiyon, ateş, hipotermi) çocuklarda önemli presipitan faktörler olarak ortaya çıkmaktadır $(2,3,6,7,13)$. Yoğun bakım ortamında çoklu ilaç kullanımı da hem predispozan hem de presipitan deliryum nedeni olarak değerlendirilmektedir $\quad(2,5,6,13-15)$. Özellikle kritik sağlık durumu nedeniyle mekanik ventilasyon desteğine ihtiyaç duyan çocuklarda ağrıyı kontrol altına almak, sedasyon ve konfor sağlamak için sıklıkla kullanılan sedatifler, opioid analjezikler ve benzodiazepinin deliryum gelişimi için bağımsız ve güçlü risk faktörleri olduğu bilinmektedir $(6,16,17)$.

Yoğun bakım ortamının gürültülü ve stresli olmasının deliryum gelişimindeki etkisine yönelik yapılan son çalışmalar, çevresel faktörlerin deliryum tablosunun gelişimine katkı sağladığını göstermektedir. Yoğun bakım ünitelerinin çocuğun alıştığı ortamdan farklı ve gürültülü olması, parlak 1şıklar, tıbbi cihazların varlığı, hasta odasında pencere bulunmaması ve sağlık profesyonellerinin tekrarlayan müdahaleleri önemli presipitan faktörlerdir $(3,4,6,9,13)$. 
Tablo 1: Pediatrik deliryum risk faktörleri

\begin{tabular}{|l|l|}
\hline $\begin{array}{l}\text { Predispozan Faktörler } \\
\text { Erken yaş }\end{array}$ & $\begin{array}{l}\text { Presipitan Faktörler } \\
\text { Erkek cinsiyet }\end{array}$ \\
Gelişimsel gerilik & Hengesizlikleri \\
Psikolojik ya da da $\quad$ yemodinamik & dengesizlikler \\
duygusal bozukluklar & Mekanik ventilasyon \\
Kronik hastalık varlığı & Oksijen yetersizliği \\
Anksiyete bozukluğu & Sedasyon, immobilite \\
Aile öyküsünde & Sepsis \\
deliryum olması & Metabolik bozukluklar \\
Bakım vericinin & Gürülttülü ve yüksek 1şıklı \\
değişkenliği/ olmaması & çevre/ uykusuzluk
\end{tabular}

Tüm faktörler bir araya geldiğinde çocukların stresini artırması ve uyku-uyanıklık döngüsünde bozulmaya yol açması nedeniyle pediatrik deliryum görülme sıklığı artmaktadır $(4,6,9)$. Önemli presipitan faktörlerden olmasına rağmen yoğun bakımda kalış süresinin uzunluğu, ağrının kontrolünün sağlanamaması ve postoperatif dönemdeki fiziksel kısıtlamalar gibi tedavi süreci ve çevre ile ilişkili faktörler deliryum değerlendirmesi sırasında gözden kaçabilmektedir $(1-3,7)$.

\section{Pediatrik Deliryumu Tanılama ve}

\section{Değerlendirme Araçlarının Kullanımı}

Deliryumu erken dönemde tanılamak, çocukların tedavisinin sağlanması için oldukça önemlidir. Ancak literatürde deliryum belirti ve bulgularının çocuk yaş ve bilişsel özelliklerine göre çeşitlilik göstermesi, deliryuma ait davranışsal belirtilerin ağrı, stres ve yoksunluk sendromu ile örtüşmesi nedeniyle anlamlı belirti gösteren çocukların yalnızca üçte birinin tespit edildiği belirtilmektedir $(3,5,7,13)$. Ayrıca çocuklarda deliryumun en sık görülen tipi olan hipoaktif deliryum belirtileri açısından sıklıkla depresyon tanısı ile karıştırılmaktadır $\quad(1,14)$ Kudchadkar ve arkadaşlarının (2014) pediatri yoğun bakım ünitelerinde çalışan sağlık profesyonellerinin deliryumu tanılamaya yönelik uygulamalarını değerlendirildiği $\quad$ araştırmada sağlık profesyonellerinin sadece $\% 7^{\prime}$ 'sinin rutin deliryum taraması yaptıkları, \%71'inin hiç deliryum taraması yapmadıkları bildirilmekte olup deliryum değerlendirmesinin yetersizliği vurgulanmaktadır (18). Staveski ve arkadaşları (2018) pediatri yoğun bakım ünitelerinde kalp cerrahisi sonrası deliryum 
yönetimini inceledikleri çok merkezli bir çalışmada

katılımcıların \%94'ünün hastalarını pediatrik deliryum yönünden değerlendirilmediğini tespit etmiştir (19).

Yoğun bakım ünitelerinde DSM-V deliryum tanı kriterleri temel alınarak geliştirilen; her yaş ve gelişim düzeyine uygun, gelişim geriliği bulunan çocuklar için de pediatrik deliryumun spesifik değerlendirilmesinde kullanılabilen dört temel değerlendirme aracı bulunmaktadır. Yoğun Bakım Ünitesinde Pediatrik Konfüzyon Değerlendirme Ölçeği, Yoğun Bakım Ünitesinde Okul Öncesi Konfüzyon Değerlendirme Ölçeği, Cornell Pediatrik Deliryum Değerlendirme Ölçeği ve Pediatrik Anestezi Deliryum Skalası sedatize ve sözlü iletişim kurulamayan çocuklar için de deliryum değerlendirmesinde kullanılmaktadır $(3,4,6,19,20)$. Staveski ve arkadaşları (2018) rutin pediatrik deliryum değerlendirmesi yaptığını bildiren katılımcıların \%39'unun Yoğun Bakım Ünitesinde Pediatrik Konfüzyon Değerlendirme Ölçeğini (pCAM-YBÜ), \%31'inin Cornell Pediatrik Deliryum Değerlendirme Ölçeğini kullandığını bildirmektedir (19). Bu değerlendirme araçlarının amacı yoğun bakımlarda pediatrik deliryum değerlendirmelerinin hızlı, güvenli ve standart yapılmasını ve kolay tanılanabilir olmasını sağlamaktır (2). Değerlendirme araçlarının kullanımı ile pediatrik deliryum erken dönemde saptanmakta, akut değişiklikler fark edilmekte, sağlık profesyonellerinin deliryum farkındalığı artmakta, hata yapma ihtimali azalmakta, hastanın güvenliği artmakta ve sağlik profesyonellerinin arasındaki iletişim kolaylaşmaktadır (4).

\section{Pediatrik Deliryumun Önlenmesi ve Yönetimi}

Pediatrik deliryum yönetiminde temel nokta deliryum henüz gelişmeden önce nonfarmakolojik yöntemlerle önlenmesi ve geliştikten sonra altta yatan nedenin farmakolojik/nonfarmakolojik tedavisidir $(3,6,7,16)$. Deliryumun önlenmesi için yapılması gereken en önemli uygulama ise deliryum gelişimine neden olan presipitan ve predispozan risk faktörleri ile hastada göğüs tüpü, endotrakeal tüp ve nazogastrik tüp bulunmas1, mesane kateterizasyonu, invaziv monitorizasyon, mekanik ventilasyon, dışkı ve idrar retansiyonu gibi iyatrojenik risk faktörlerinin kontrol altına alınmasıdır. Bu amaçla yoğun bakım ünitesinde yatmakta olan hastaların risk faktörleri açısından kapsamlı değerlendirilmesi önemlidir $(21,22)$. 


\section{Nonfarmakolojik Yönetimi}

Pediatrik deliryumu önleme ve yönetimine ilişkin uygulamaların belirlendiği araştırmalarda hastanın erken mobilizasyonu, çevresel faktörlerin düzenlenmesini, $\quad$ sağlıklı uyku-uyanıklık döngüsünün sağlanmasını ve aile merkezli bakım verilmesini içeren nonfarmakolojik stratejiler üzerinde durulmaktadır $(2,4,6,9,18)$.

\section{Erken Mobilizasyon}

Hastanın klinik durumu uygun ise erken mobilizasyon yoğun bakım ünitelerinde pediatrik deliryumun görülme sıklığını ve komplikasyonlarını azaltmak için önerilmektedir. Erken mobilizasyonun sağlanması için; intravenöz ve foley kateter kullanımından kaçınılması ve aktif/pasif ROM egzersizlerinin yapılması gibi uygulamaları içeren özel bir protokol oluşturulması; hasta ve bakım vericilerinin yanı sira tüm sağlık profesyonellerine immobilizasyonun zararları hakkında eğitim verilmesi önemlidir $(6,23)$.

Pediatri yoğun bakım ünitelerinde erken mobilizasyon uygulamasının etkilerinin incelendiği çalışmalarda erken mobilizasyonun

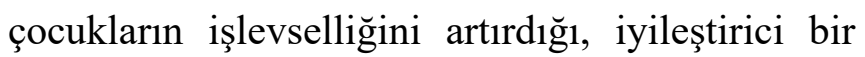

ortam sağladığı, pediatrik deliryum gibi tedavi ile ilişkili komplikasyonlarda anlamlı bir azalma olduğu ve hospitalizasyon süresini kısalttığ saptanmıştır $(24,25)$. Benzer şekilde, Simone ve arkadaşları (2017) pediatri yoğun bakım ünitelerinde hastalara uyguladıkları sedasyon ve erken mobilizasyon protokolü sonrasında pediatrik deliryum görülme sıklığının \%19,3’ den \%11,84'e düştügüünü tespit etmiştir (26).

\section{Çevresel Faktörlerin Düzenlenmesi}

Yoğun bakım ünitesindeki gürültü, sürekli 1şık, kokular, invaziv olan ve olmayan müdahaleler, anlamlı sözel ve bilişsel uyaranların eksikliği, sosyal izolasyon, immobilizasyon, uyku bozuklukları, 1s1, cereyan, ortamda pencere olmaması ve fiziksel kısitlama uygulanması çevresel risk faktörlerini oluşturmaktadır $(27,28)$. Dünya Sağlık Örgütü (DSÖ) yoğun bakım ünitelerinde ses seviyesinin gündüz 35 desibel, gece ise 30 desibelden düşük olmasını, monitör ve diğer tıbbi ekipmanlardaki alarm ses seviyelerinin kısılmasını ve ünitede her türlü gürültüyü kısıtlayacak önlemin alınmasını önermektedir (18). Weatherhead ve arkadaşları (2016) pediatri yoğun bakım ünitelerinin kullanılmayan alanlarında bile 
ses seviyesinin önerilenden yüksek olduğunu saptamış, gürültü nedeniyle çocukların bilişsel fonksiyonlarının bozularak deliryum görülme sıklığının artabileceğini vurgulamıştır (29). Benzer şekilde literatürde pediatri yoğun bakım ünitelerinde gürültünün uyku, stres ve iyileşme sürecini olumsuz etkileyerek pediatrik deliryum gelişmesine sebep olduğu, gürültü seviyesinin azalması ile deliryum görülme sıklığının azaldığı saptanmıştır $(30,31)$.

Yoğun bakım ünitesinin aydınlatılmasının da sirkadiyen ritmi etkileyerek pediatrik deliryum gelişimine yatkınlığı artırması nedeniyle çocuk odalarının gün ışığını alacak şekilde planlanması ve uygun aydınlatmanın sağlanması için göz bandı kullanımı önerilmektedir $(3,4,6,9,18)$. Yoğun bakım ünitesinde tedavi gören hastalarda kulaklık ve göz bandı kullanımının uyku kalitesi üzerindeki etkisinin incelendiği araştırmalarda kontrol grubuna oranla deney grubunun uykuya daha kolay daldığı, deney grubunda yer alan hastaların uykularının daha az bölündügü, kulaklık ve göz bandının birlikte kullanımının deliryum görülme sıklığını \%53 oranında azaltabileceği bildirilmiştir $(31,32,33)$.
Yoğun bakım ünitelerinde sosyal izolasyon ve duyusal yoksunluk oryantasyonun bozulmasina neden olmakta ve deliryuma katkıda bulunmaktadır $(3,6,18)$. Çocuğa ebeveynleri ve sağlık profesyonelleri tarafindan günlük bakım faaliyetleri ve tedavisi hakkında sürekli bilgi sağlanarak oryantasyonu sağlanmalı ve iletişimi desteklenmelidir. Oryantasyonun sağlanması için özellikle büyük çocukların odasına takvim ve saat koyulması, daha küçük çocukların odasına gündüz güneş gece ay resminin asılması, odasının ve yatağının değiştirilmemesi de önerilmektedir $(3,4,6,18)$. Ayrıca yoğun bakım ortamında bakım vericinin sürekliliğinin sağlanması, çocuğun sevdiği eşyaların (her zaman uyuduğu battaniye, emzik, oyuncak) getirilmesi, aile ve arkadaşlarının fotoğraflarının odasına asılması vb uygulamalar ile yoğun bakım ortamının tanıdık, güvenilir ve rahatlatıcı ev ortamına dönüştürülmesi korku ve kaygıyı azaltmaktadır $(3,4,6,9,13,34)$. Kim ve arkadaşlarının (2019) pediatrik deliryum ile ilişkili faktörleri araştırdığı çalışmada tanıdık obje kullanılmasının pediatrik deliryum görülme sıklığını \%24,5 azalttı̆̆ bildirilmiştir (34). 


\section{Sağlıklı Uyku-Uyanıklık Döngüsünün}

\section{Desteklenmesi}

Yoğun bakım ünitelerinde çocukların uykuuyanıklık döngüsünün bozulması iyileşme sürecinin gecikmesine, stresin artmasına ve bilişsel fonksiyonlarının bozulmasına neden olarak pediatrik deliryum gelişmesini tetiklemektedir (4). Literatürde çocukların sağlıklı uyku-uyanıklık döngüsünün sağlanabilmesi için uygun aydınlatma ve gürültünün azaltılması gibi önlemlerin yanı sıra banyo, beslenme gibi konularda rutinlerinin sürdürülmesinin, tedavi ve bakımın toplu şekilde yapılarak çocuğa uyku ve dinlenme firsatı tanınmasının önemi vurgulanmaktadır $(4,6,9)$. Patel ve arkadaşları (2014) yoğun bakım ünitesinde nonfarmakolojik yöntemlerle uyku ölçümlerinde düzelme meydana gelen hastalarda deliryum görülme sıklığının \%33’ten \%14'e düştüğünü bildirmiştir (35). Benzer olarak, Atalan ve arkadaşları (2013) kalp cerrahisi geçiren hastalarda deliryum ve uyku kalitesi arasında anlamlı bir ilişki olduğunu saptamıştır (36).

\section{Aile Merkezli Bakım Verilmesi}

Yoğun bakım ünitelerinde tedavi gören çocukların bakım sağlayıcılarından uzak kalması analjezik gereksinimini artırarak, iyileşme sürecini yavaşlatarak ve hospitalizasyon süresini uzatarak pediatrik deliryum gelişimine yol açmaktadır $(9,37,38)$. Aile merkezli bakım çocuğun bilişsel, fiziksel ve psikolojik fonksiyonlarını desteklemesinin yanına sıra ailenin sağlık profesyonelleri ile iş birliğini de artırmaktadır (38). Ebeveynler çocuklarının davranış değişikliklerini kolayca fark etmeleri ve sağlık profesyonellerini bilgilendirmeleri sonucunda pediatrik deliryumun tanılanmasının gecikmesi önlenmektedir (9). Garrors ve arkadaşları (2019) yoğun bakım ünitelerinde aile varlığının hastalarının kaygı ve stresini azalttığını bildirmiştir (39). Ancak Rosa ve arkadaşları (2019) yaptıkları randomize kontrollü çalışmada aile merkezli bakım uygulamasının pediatrik deliryum insidansına anlamlı derecede etki etmediğini tespit etmiştir (40).

\section{Farmakolojik Yönetimi}

Pediatrik deliryumun yönetiminde en uygun farmakolojik yaklaşım pediatrik deliryumun gelişimine neden olabilecek ilaçlardan kaçınmaktır. Ancak kendisine ve çevresine zarar veren çocuklarda davranışsal bozuklukların kontrolü için farmakolojik müdahale gerekli 
olmaktadır $(4,6)$. Tıbbi tedavi çoğunlukla hasta ve ailenin rahatsızlığını en aza indirmek ve hastanın güvenliğini sağlamak için gereklidir. Hastayı sedatize etmek değil, bilinci açık, sakin, iletişim kurulabilir hale getirmek hedeflenmelidir $(3,4)$.

Deliryum semptomlarının tedavisinde ideal bir ilaç tedavisi yoktur. Genellikle antipsikotik ilaçlar tercih edilmektedir. Antipsikotiklerin deliryum tedavisinde etkinliğini gösteren randomize kontrollü çalışmalar çoğunlukla erişkin popülasyon için yapılmış olmasına rağmen; pediatrik deliryumun farmakolojik yönetiminde de yaygın olarak kullanılmaktadır ve nörotransmitterlerdeki düzensizliği gidererek tedavide etki gösterdiği düşünülmektedir $(3,4,22)$. Antipsikotiklerin sedatif etkisi vardır ve sağlıklı uyku-uyanıklık döngüsünün sağlanmasına da fayda sağlamaktadır. Ancak çocuk psikiyatristine danışılmadan başlanmaması gerekmektedir (3). Antipsikotikler gerekli durumlarda düşük dozda başlanmalı, yan etkileri mutlaka göz önünde bulundurulmal1, çocuğun tedaviye yanıtına, yapılan sürekli değerlendirmelere göre dozu ayarlanmalı ve tıbbi gereklilik durumu ortadan kalkınca dozu azaltılarak kesilmelidir $(3,4,7)$.

\section{Pediatrik Deliryum Yönetiminde Hemşirenin Rolü}

Yoğun bakım hemşireleri, çocuklarla en fazla iletişimde olan ve onlara sürekli bakım veren sağlık profesyonelleri olarak çocuklardaki fizyolojik ve davranışsal her değişikliği kolayca fark edebilmeleri nedeniyle pediatrik deliryumun önlenmesi, erken tanılanması ve müdahale edilmesi için kritik önemi bulunmaktadır $(2,6,41)$. $\mathrm{Bu}$ nedenle hemşirelerin pediatrik deliryumu, risk faktörlerini, belirti ve bulgularını, değerlendirme ve yönetimini iyi bilmeleri gerekmektedir (6). Pediatrik deliryumun nonfarmakolojik yönetiminden primer sorumlu olan sağlık profesyonelleri hemşirelerdir (41). Hemşirelik bakımında nonfarmakolojik yöntemlerin kullanımı pediatrik deliryumun ve komplikasyonlarının önlenmesini kolaylaştırmakta, farmakolojik yöntemlerin kullanımını da azaltmaktadır $(2,22)$. Tıbbi tedavinin gerekli olduğu durumlarda ise hemşireler çocukları tedavinin yan etkilerine ve hedef sedasyon seviyesine yönelik takip etmektedir. Hemşirelerin çocuklarda gelişen davranışsal, fizyolojik ve bilişsel değişikliklere yönelik değerlendirmelerinin sonucunda hedef 
sedasyon seviyesi için ihtiyaç duyulan tıbbi tedavinin dozunun ayarlanması önemlidir $(2,20)$.

Hemşirelik bakımı planlanırken deliryumun tipinin de dikkate alınması gerekmektedir. Özellikle hipoaktif deliryum belirtileri gözden kaçabildiği ve depresyon ile karıştırılabildiği için tanılanması daha zor olmakta ve uygun müdahale gecikebilmektedir $\quad(14,19,21) . \quad$ Hiperaktif deliryumda ise çocuklar sağlı profesyonelleri ile iş birliği yapmamakta ve yapılan uygulamaları reddetmektedir (42). Her iki deliryum tipi de yönetimi zor ve karmaşık bir süreçtir. Bu nedenle literatürde hemşirelerin pediatrik deliryum değerlendirmesinde standart bir değerlendirme formu kullanmaları, değerlendirme sonuçlarını nöbet teslimi sırasında devrederek bakımı standartlaştırması ve yapılan değerlendirmeler doğrultusunda çocuk psikiyatristi konsültasyonu istenilmesi önerilmektedir $(1,6)$.

Hemşirelerin deliryum yönetiminde çocuğun kendini güvende hissetmesi ve içinde bulunduğu farklı ortamın tehlikeli olmadığını düşünmesi için primer hemşirelik uygulamasının önemi vurgulanmaktadır $(20,43)$. Bakım veren primer hemşire çocuğa kendini tanıtarak tedavi süresince hangi sağlık profesyonelinin hangi rolü üstlendiğini ve hangi uygulamanın neden yapıldığını açıklamalı, sakin ve yavaş konuşmalı, anlaş1lır ve kısa cümleler kurmalı ve çocuğun bağımsızlığını desteklemelidir (20). Çocuğa ismiyle hitap etmek, göz teması kurmak oryantasyonunu desteklemekte ve güven sağlamaktadır. Aynı zamanda çocukların kendilerini ifade etmelerini sağlamak için açık uçlu sorular sorulması ve davranışsal ifadelerinin de dikkate alınması gerekmektedir $(20,44)$.

\section{SONUÇ}

Yoğun bakım ünitelerinde tedavi gören çocuk hastalarda sık görülen deliryum; hospitalizasyon süresinin uzamasına, mortalite ve morbidite oranlarının artmasına neden olan önemli bir sendromdur (3-5,7). Görülme sıklığı yüksek olmasına rağmen pediatrik deliryumun tanılanması gecikebilmekte, komplikasyonlar gelişebilmekte ve hastalar kaybedilebilmektedir (3-5). Yoğun bakım hemşireleri hastalarla en fazla iletişimde olan ve onlara sürekli bakım veren sağlık profesyonelleri olmaları nedeniyle pediatrik deliryumun önlenmesi, erken tanılanması ve müdahale edilmesi için kritik önemi bulunmaktadır 
$(2,6,41) . \mathrm{Bu}$ derleme ile pediatrik deliryumun önlenmesi ve yönetimine ilişkin hemşirelerin rol ve sorumlulukları vurgulanmaya çalışılmıştır.

Pediatrik deliryuma yönelik kanıt düzeyi yüksek

bilgiler yeterli düzeyde olmadığından randomize

kontrollü çalışmalara gereksinim olduğu

düşünülmektedir. Pediatrik deliryumun

önlenebilmesi ve etkin yönetilebilmesi için yapılan

çalışmaların arttırılması, araştırma sonuçlarının

klinik uygulamaya yansitılarak pediatrik deliryuma

ilişkin protokoller ve bakım kılavuzlarının

oluşturulması ve yoğun bakım hemşirelerine eğitim

programları düzenlenmesi önerilmektedir.

\section{KAYNAKLAR}

1. Flaigle MC, Ascenzi J, Kudchadkar SR. Identifying barriers to delirium screening and prevention in the pediatric icu: evaluation of picu staff knowledge. J Pediatr Nurs. 2016; 31(1): 81-4.

2. Traube C, Silver G, Reeder RW, Doyle H, Hegel E, Wolfe HA, et al. Delirium in critically ill children: an international point prevalence study. Crit Care Med. 2017; 45(4): 584-90.

3. Turkel S, Hanft A, Epstein D, Jacobson J. Review of Delirium in the pediatric intensive care unit. J of Pediatr Intensive Care. 2013; 2(4): 169-76.

4. Bettencourt A, Mullen JE. Delirium in children: identification, prevention, and management. Crit Care Nurse. 2019; 37(3): 9-18.

5. Ouimet S, Kavanagh BP, Gottfried SB, Skrobik Y. Incidence, risk factors and consequences of icu delirium. Intensive Care Med. 2007; 33: 66-73.

6. Norman S, Taha AA, Turner HN. Delirium in the critically ill child. Clin Nurse Spec. 2017; 31(5): 276-84.

7. Bryant K. Pediatric delirium in the cardiac intensive care unit identification and intervention. Crit Care Nurse. 2018; 38(4): 1-7.

8. Colville G, Kerry S, Pierce C. Children's factual and delusional memories of intensive care. Am J Resp Crit Care Med. 2008; 177(9): 976-82.

9. Holly C, Porter S, Echevarria M, Dreker M, Ruzehaji S. Recognizing delirium in hospitalized children a systematic review of the evidence on risk factors and characteristics. Am J Nurse. 2018; 118 (4): 24-36.

10. Çınar MA, Balıkçı A, Sertoğlu E, Ak M, Serdar MA, Özmenler KN. Deliryum patofizyolojisinde CRP, TNF- $\alpha$ ve IGF-1'in rolü. Nöropsikiyatri Arşivi. 2014; 51: 376-82.

11. Kaya E, Sönmez S, Barlas F. Deliryum. Okmeydanı Tıp Dergisi. 2013; 29 (Ek say1 2):70-4.
12. Hipp DM. Pharmacological and non-pharmacological management of delirium in critically ill Patients. Neurotherapeutics. 2012; 9 (1): 15875.

13. Hatherill S, Flisher AJ. Delirium in children and adolescents a systematic review of the literatüre. J Psychosom Res. 2010; 68(4): 337 44

14. Franken A, Sebbens D, Mensik J. Pediatric delirium: early identification of barriers to optimize success of screening and prevention. J Pediatr Health Care. 2019; 33(3): 228-233.

15. Özdemir L. Yoğun bakım hastasında deliryumun yönetimi ve hemşirenin sorumlulukları. Hacettepe Üniversitesi Hemşirelik Fakültesi Dergisi. 2014; 1(1): 90-8.

16. Ista E, Beest H, Rosmalen J, Hoog M, Tibboel D, Beusekom B, et al. Sophia observation withdrawal symptoms- pediatric delirium scale: a tool for early screening of delirium in the picu. Aust Crit Care. 2018; 31(5): 266-73.

17. Patel AK, Biagas KV, Clarke EC, Gerber LM, Mauer E, Silver G, et al. Delirium in children after cardiac bypass surgery. Pediatr Crit Care Med. 2017; 18(2): 165-71.

18. Kudchadkar SR, Yaster M, Punjabi NM. Sedation, sleep promotion, and delirium screening practices in the care of mechanically ventilated children: a wake-up call for the pediatric critical care community. Crit Care Med. 2014; 42(7): 1592-600.

19. Staveski SL, Pickler RH, Lin L, Shaw RJ, Meinzen-Derr J, Redington A, et al. Management of pediatric delirium in pediatric cardiac intensive care patients: an international survey of current practices. Pediatr Crit Care Med. 2018; 19(6): 538-43.

20. Traube C, Silver G, Kearney J, Patel A, Atkinson TM, Yoon MJ, et al. Cornell assessment of pediatric delirium: a valid, rapid, observational tool for screening delirium in the picu, Crit Care Med. 2014; 42(3): 656-63.

21. Traube C, Augenstein J, Greenwald B, LaQuaglia M, Silver G. Brief report neuroblastoma and pediatric delirium: a case series. Pediatr Blood Cancer. 2014; 61(6): 1121-3.

22. Thom RP. Pediatric Delirium. Am J Psychiatry. 2017; 12(2): 6-8.

23. Johnston C, Krebs VLJ, Carvalho WB, Sampaio MC. Early mobilization in picu: are we on time?. Pediatrics in South America. 2019; 5: 397-405.

24. Wieczorek B, Ascenzi J, Kim Y, Lenker H, Potter C, Shata NJ, et al. Picu up!: impact of a quality improvement intervention to promote early mobilization in critically ill Children. Pediatr Crit Care Med. 2016; 17(12): 559-66.

25. Schweickert WD, Pohlman MC, Pohlman AS, Nigos C, Pawlik AJ, Esbrook CL, et al. Early physical and occupational therapy in mechanically ventilated, critically ill patients: a randomised controlled trial. Lancet. 2009; 373(9678): 1874-82.

26. Simone S, Edwards S, Lardieri A, Walker LK, Graciano AL, Kishk OA, et al. Implementation of an icu bundle: an interprofessional quality improvement project to enhance delirium management and monitor delirium prevalence in a single picu. Pediatr Criti Care Med. 2017; 18(6): 531-40.

27. Arend E, Christensen M. Delirium in the intensive care unit: a review. Nurs Crit Care. 2009; 14(3): 145-54.

28. Sarı N. Sağlık çalışanlarının yoğun bakımlarda deliryum yönetimlerinin incelenmesi, Yüksek Lisans Tezi, İzmir, Ege Üniversitesi Sağlık Bilimleri Enstitüsü, 2015.

29. Weatherhead J, Niedner M, Kahoud R, Kawai Y. Noise pollution in a pediatric intensive care unit. Crit Care Med. 2016; 44 (12): 350.

30. Kawai Y, Weatherhead JR, Traube C, Owens TA, Shaw BE, Fraser EJ, et al. Quality improvement initiative to reduce pediatric intensive care unit noise pollution with the use of a pediatric delirium bundle. J Intensive Care Med. 2019; 34(5): 383-90.

31. Rompaey BV, Elseviers MM, Drom WV, Fromont V, Jorens PG. The effect of earplugs during the night on the onset of delirium and sleep perception: a randomized controlled trial in intensive care patients. Crit Care Med. 2012; 16(3): 1-10.

32. Guen ML, Robin AN, Lebard C, Arnulf I, Langeron O. Earplugs and eye masks vs routine care prevent sleep impairment in post-anaesthesia care unit: a randomized study. Br J of Anaesth. 2014; 112 (1): 89-95.

33. Yazdannik AR, Zareie A, Hasanpour M, Kashef J. The effect of earplugs and eye mask on patients' perceived sleep quality in intensive care unit. Iranian J Nursing Midwifery Res. 2014; 19 (6): 673-8.

34. Kim HJ, Kim DH. Factors associated with Pediatric Delirium in the Pediatric Intensive Care Unit. Child Health Nurs Res. 2019; 25 (2): 103-11. 
35. Patel J, Baldwin J, Bunting P, Laha S. The effect of a multicomponent multidisciplinary bundle of interventions on sleep and delirium in medical and surgical intensive care Patients. Anaesth. 2014; 69: 5409.

36. Atalan N, Sevim ME. Postoperative delirium associated with prolonged decline in cognitive function and sleep disturbances after cardiac surgery. Türk Göğüs Kalp Damar Cerrahisi Dergisi. 2013; 21 (2): 35863.

37. Tosun A, Tüfekci G. Çocuk kliniklerinde aile merkezli bakım uygulamalarının incelenmesi. Anadolu Hemșirelik ve Sağlık Bilimleri Dergisi. 2015; 18 (2): 131-9.

38. Boztepe H. Pediatri hemşireliğinde aile merkezli bakım. Türkiye Klinikleri J Nurs Sci. 2009; 1(2): 88-93.

39. Bauer PR, Rabinstein AA, Wilson ME. Family Visitation Policies in the ICU and Delirium. JAMA. 2019; 322 (19): 1923-5.

40. Rosa RG, Kochhann R, Barbosa MG, Cavalcanti AB, Pellegrini JAS, Ayres LO, et al. Effect of flexible family visitation on delirium among patients in the intensive care unit the icu visits randomized clinical trial. JAMA. 2019; 322 (3): 216-28.

41. Simonsen BY, Lisby M, Traube C, Skovby P. The cornell assessment of pediatric delirium: translation and inter-rater reliability in a danish pediatric intensive care unit. Acta Anaesthesiol Scand. 2019; 63 (7): 900-4.

42. Schieveld JNM, Janssen JNF. Delirium in the pediatric patient on the growing awareness of 1 ts clinical interdisciplinary importance. JAMA Pediatr. 2014; 168(7): 595-6.

43. Smith HAB, Gangopadhyay M, Goben CM, Jacobowski NL, Chestnut $\mathrm{MH}$, Savage S, et al. The preschool confusion assessment method for the icu (pscam-icu): valid and reliable delirium monitoring for critically ill infants and children. Crit Care Med. 2016; 44(3): 592-600.

44. Şahin H. Bir üniversite hastanesinde çalışan hemşirelerin deliryum hakkındaki bilgi ve tutumlarının araştırılması, Yüksek Lisans Tezi, Avrasya Üniversitesi Sağlık Bilimleri Üniversitesi, Trabzon, 2019. 